\title{
Performance of a Predictive Model to Identify Undiagnosed Diabetes in a Health Care Setting
}

\author{
Caroline A. BaAn, MSC \\ JOHANNES B. RUIGE, MD \\ RONALD P. STOLK, MD \\ Jacqueline C.M. Witteman, PhD
}

\author{
JACQUeline M. DeKKeR, PHD \\ ROBERT J. HEINE, PROF \\ EDITH J.M. FESKENS, PHD
}

OBJ ECTIVE - To develop a predictive model to identify individuals with an increased risk for undiagnosed diabetes, al lowing for the availability of information within the health care system.

RESEARCH DESIGN AND METHODS - A sample of participants from the Rotterdam Study $(n=1,016)$, aged $55-75$ years, not known to have diabetes completed a questionnaire on diabetes-related symptoms and risk factors and underwent a glucose tolerance test. Predictive models were developed using stepwise logistic regression analyses with the absence or presence of newly diagnosed diabetes as the dependent variable and various items with a plausible connection to diabetes as the independent variables. The models were evaluated in another Dutch population-based study, theHoorn Study $(n=2,364)$, in which the participants were aged 50-74 years. Performances of the predictive models were compared by using receiver-operator characteristics (ROC) curves.

RESULTS - We developed three predictive models (PMs). PM 1 contained information routinely collected by the general practitioner, while PM2 also contained variables obtainable by additional questions. The third predictive model, PM3, included variables that had to be obtained from a physical examination. These latter variables did not have additive predictive value, resulting in a PM3 similar to PM2. The area under the ROC curve was higher for PM2 than for PM 1, but the $95 \%$ Cls overlapped (0.74 [0.70-0.78] and 0.68 [0.64-0.72], respectively).

CONCLUSIONS - Using only information normally present in the files of a general practitioner, a predictive model was developed that performed similarly to one supplemented by information obtained from additional questions. The simplicity of PM 1 makes it easy to implement in the current health care setting.

Diabetes C are22:213-219, 1999

$\mathrm{S}$ everal studies have reported that up to $50 \%$ of all subjects with diabetes are undiagnosed (1-4). Although these subjects are not aware of their disease, they are at risk for the micro- and macrovascu- lar complications of diabetes $(5,6)$. Early treatment of diabetes and the associated cardiovascular risk factors (hypertension, obesity, dyslipidemia) may reduce the occurrence of these complications (7).

\footnotetext{
$\bullet \bullet \bullet \bullet \bullet \bullet \bullet \bullet \bullet \bullet \bullet \bullet \bullet \bullet \bullet \bullet \bullet \bullet \bullet \bullet \bullet \bullet \bullet \bullet \bullet \bullet \bullet \bullet \bullet \bullet \bullet \bullet \bullet \bullet \bullet \bullet \bullet \bullet \bullet \bullet \bullet \bullet \bullet \bullet \bullet \bullet \bullet \bullet \bullet$

From the Department of Public Health (C.A.B.) and the Department of Epidemiology and Biostatistics (J.C.M.W.), Erasmus University, Rotterdam; the Institute for Research in Extramural Medicine (J.B.R., J.M.D., R.J.H.), Vrije Universiteit, Amsterdam; the Julius Center for Patient Oriented Research (R.P.S.), Utrecht U niversity, Utrecht; and the Department for Chronic Disease and Environmental Epidemiology (E.J.M.F.), National Institute of Public Health and the Environment, Bilthoven, the N etherlands.

Address correspondence and reprint requests to Caroline A. Baan, Department of Public Health, Erasmus University Rotterdam, PO Box 1738, 3000 DR Rotterdam, the N etherlands. E-mail: baan@mgz.fgg.eur.nl.

Received for publication 30 June 1998 and accepted in revised form 20 October 1998.

Abbreviations: ADA, American Diabetes Association; IGT, impaired glucose tolerance; OGTT, oral glucose tolerance test; PM, predictive model; PPV, positive predictive value; ROC, receiver-operator characteristics; WHO, World Health Organization; WHR, waist-to-hip ratio.

A table elsewhere in this issue shows conventional and Système International (SI) units and conversion factors for many substances.
}

Therefore, early detection of subjects with undiagnosed diabetes might be of importance in reducing the burden of complications of diabetes. Identifying people at increased risk for undiagnosed diabetes, followed by blood glucose testing to establish diagnosis, is considered to bean appropriate way of dealing with this problem (8). The American Diabetes Association (ADA) recommends screening for type 2 diabetes by using a verbal or written questionnaire to select high-risk individuals to increase the cost-effectiveness of testing undiagnosed individuals (9).

A number of questionnaires have been developed to identify subjects with an increased risk of undiagnosed diabetes (10-12). However, a tool based on information al ready available to a general practitioner would be more easily implemented in the current health care setting. In a sample of the Rotterdam Study in the Netherlands, we developed a predictive model to identify individuals at increased risk for undiagnosed diabetes, using information routinely collected by the general practitioner. In addition, we developed predictive models using information collected by simple questions or physical examination. These predictive models were tested in the Hoorn Study, another Dutch populationbased study (3), and their diagnostic value is evaluated in this study.

\section{RESEARCH DESIGN AND METHODS}

\section{Rotterdam Study}

The present study was conducted among participants of the Rotterdam Study (13). The selection of the study sample is described in detail elsewhere (14). A baseline examination was conducted from 1990 to 1993 and included 7,983 subjects aged $\geq 55$ years (response rate $78 \%$ ). Based on the baseline nonfasting oral glucose tolerance test (OGTT), participants aged 55-75 years were temporarily classified as diabetic (using medication or random or postload level $>11.1 \mathrm{mmol} / \mathrm{l}$ ), hyperinsulinemic (upper quintile of the gender-specific postload insulin distribution in subjects without 
impaired glucose tolerance [IGT] or diabetes) or normal glucose tolerant. A stratified random sample was taken from each group to participate in the Rotterdam Diabetes Study. The overall response rate in the follow-up examination was $90 \%$, and 1,112 subjects took part in the diabetes study. In this study, a definitive classification of the glucose tolerance status was made, based on a fasting O GTT.

The participants came to the research center after an overnight fast (no food intake after 11:00 P.M.), and had blood taken between 8:00 and 9:00 A.M. Subjects not using antidiabetic medication went on to have a standard 75-g OGTT (15). Fasting and 2-h plasma glucose levels were determined using the glucose hexokinase method. Diabetes was defined as the use of antidiabetic medication (insulin or oral hypoglycemic medication) and/or a 2-h plasma glucose concentration $\geq 11.1$ $\mathrm{mmol} / \mathrm{l}$ according to World Health Organization (W HO) criteria (15). Subjects with a glucose level in the diabetic range who did not use antidiabetic medication were classified as newly diagnosed cases of diabetes. All known diabetic patients $(n=69)$ were excluded from the present analysis.

Information on medication use, medical history (cardiovascular disease, stroke), smoking habits, and family history (first degree) of diabetes was obtained from a selfadministered questionnaire. The Rose questionnai re was used to assess angina pectoris and intermittent claudication (16). Physical activity was assessed by a self-administered questionnaire derived from one originally designed for retired men and described by Caspersen et al. (17). This was modified for use in the current study by the addition of questions of household activities (14).

Sitting blood pressure was measured with a random-zero sphygmomanometer, and the mean of two measurements was used in the analyses. Weight and height were measured with the participants wearing indoor clothes and no shoes. Waist circumference was measured midway between the lower rib margin and iliac crest; hip circumference was measured at the trochanter major. BMI was determined by dividing the weight by the height squared (kilograms per meter squared) and body fat distribution was assessed by means of the waist-to-hip circumference ratio (WHR).

Analysis

We used three levels of information, defined by the degree of effort needed by a general practitioner for their collection. Level 1 is normally present in routine general practitioner records, level 2 is obtainable by simplequestions, and level 3 requires additional measurements. Three predictive models were developed, based on these three levels of information. In Table 1, the variables used for analysis are grouped according to the level of information.

Within each level of information, a stepwise logistic regression analysis was used with the absence or presence of newly detected diabetes as the dependent variable and the variables of the predictive model as independent variables. Any symptom or risk factor associated with newly detected diabetes at a significance level of $P<0.05$ was included in the first predictive model. This model was extended to include the variables of the second model and, subsequently, those of the third model as well. The regression coefficients of the predictive models were transformed into scores (multiplied by 10

Table 1-Characteristics of the Rotterdam Diabetes Study population ordered by level of information

\begin{tabular}{|c|c|c|c|}
\hline \multirow[b]{2}{*}{ Variables } & \multicolumn{3}{|c|}{ Newly detected } \\
\hline & Nondiabetic & diabetes & OR $(95 \% \mathrm{Cl})$ \\
\hline$n$ & 898 & 118 & - \\
\hline \multicolumn{4}{|l|}{$\begin{array}{l}\text { Level 1: present in routine general } \\
\text { practice records }\end{array}$} \\
\hline Age (years) & $66.2 \pm 5.5$ & $67.8 \pm 5.7$ & - \\
\hline $\operatorname{Sex}(\% \mathrm{~F})$ & 51.7 & 41.5 & - \\
\hline Presence of obesity & 13.2 & 20.3 & $1.75(1.07-2.88)$ \\
\hline Use of antihypertensive medication & 24.6 & 35.6 & $1.57(1.04-2.38)$ \\
\hline Use of lipid-lowering medication & 5.3 & 6.8 & $1.29(0.59-2.82)$ \\
\hline Gestational diabetes ( $\%$ of the women) & 1 & 0 & - \\
\hline Prevalence of cardiovascular disease & 13.7 & 22.0 & $1.54(0.95-2.51)$ \\
\hline \multicolumn{4}{|l|}{ Level 2: additional questions } \\
\hline BMI $\left(\mathrm{kg} / \mathrm{m}^{2}\right)$ & $26.1 \pm 3.2$ & $27.5 \pm 3.9$ & $1.10(1.04-1.16)$ \\
\hline Family history of diabetes & 20.5 & 28.8 & $1.94(1.25-30.1)$ \\
\hline Smoking & 23.2 & 20.3 & $0.88(0.54-1.42)$ \\
\hline \multicolumn{4}{|l|}{ Cardiovascular symptoms } \\
\hline Chest pain & 6.7 & 11.0 & $1.97(1.04-3.75)$ \\
\hline Pain during walking & 4.0 & 7.6 & $2.30(1.10-4.81)$ \\
\hline $\begin{array}{l}\text { Pain during walking with } \\
\text { need to slow down }\end{array}$ & 2.9 & 3.4 & $1.10(0.38-3.19)$ \\
\hline Pain in calf during walking & 2.4 & 2.5 & $1.06(0.31-3.59)$ \\
\hline \multicolumn{4}{|l|}{ Shortness of breath when } \\
\hline Washing/dressing & 2.7 & 3.4 & $1.18(0.40-3.49)$ \\
\hline Walking with people of the same age & 4.2 & 3.4 & $0.72(0.25-2.08)$ \\
\hline Not cycling & 40.1 & 66.1 & $2.99(1.97-4.55)$ \\
\hline
\end{tabular}

Level 3: additional measurements

Diastolic blood pressure $(\mathrm{mmHg})$

Systolic blood pressure $(\mathrm{mmHg})$

$76.3 \pm 10.7 \quad 76.8 \pm 11.4 \quad 1.00(0.98-1.03)$ WHR

$135.7 \pm 19.7 \quad 143.6 \pm 20.6 \quad 1.02(1.00-1.03)$

$0.91 \pm 0.09 \quad 0.94 \pm 0.09 \quad 12.51(1.04-150.8)$

Data are means \pm SD or \%. Odds ratios (ORs) are adjusted for age and sex. O besity is defined in this study as $\mathrm{BMI} \geq 30 \mathrm{~kg} / \mathrm{m}^{2}$. Blood pressure measurements exclude those subjects using antihypertensive medication. 
Table 2- Results of stepwise logistic regression analyses predicting newly detected diabetes: the content of two predictive models (Rotterdam Diabetes Study)

\begin{tabular}{|c|c|c|c|c|c|c|c|c|c|}
\hline \multirow[b]{2}{*}{ Variables } & \multirow[b]{2}{*}{ Unit } & \multicolumn{4}{|c|}{ PM1 } & \multicolumn{4}{|c|}{ PM2 } \\
\hline & & LRC & Score & OR $(95 \% \mathrm{Cl})$ & $P$ value & LRC & Score & OR $(95 \% \mathrm{Cl})$ & $P$ value \\
\hline Constant & & -3.02 & & & & -5.42 & & & \\
\hline Age & $\begin{array}{l}\text { Per } 5 \text {-year increment } \\
\text { from } 55 \text { years }\end{array}$ & 0.19 & 2 & $1.21(1.02-1.44)$ & 0.03 & 0.13 & 1 & $1.13(0.95-1.36)$ & 0.17 \\
\hline Sex & 0 , female; 1 , male & 0.46 & 5 & $1.59(1.07-2.36)$ & 0.02 & 0.66 & 7 & $1.94(1.28-2.93)$ & 0.02 \\
\hline $\begin{array}{l}\text { Use of antihypertensive } \\
\text { medication }\end{array}$ & 0, no; 1 , yes & 0.42 & 4 & $1.53(1.00-2.32)$ & 0.04 & 0.27 & 3 & $1.31(0.85-2.03)$ & 0.22 \\
\hline Presence of obesity & 0, not obese; 1, obese & 0.51 & 5 & $1.68(1.02-2.76)$ & 0.05 & & & & \\
\hline Physical inactivity & 0 , cycling; 1 , not cycling & & & & & 1.04 & 10 & $2.83(1.85-4.33)$ & $<0.001$ \\
\hline Family history of diabetes & 0, no; 1 , yes & & & & & 0.70 & 7 & $2.01(1.28-3.18)$ & 0.003 \\
\hline BMI & Continuous & & & & & 0.07 & 1 & $1.07(1.02-1.13)$ & 0.01 \\
\hline
\end{tabular}

Scores were obtained by multiplying the regression coefficient by 10 and rounding to the nearest integer. O besity is defined as BMI $\geq 30 \mathrm{~kg} / \mathrm{m}^{2}$ for both sexes. The actual BMI of a subject has to be multiplied by 1 and added to the total sum of scores. LCR, logistic regression coefficient; OR, odds ratio.

To compare the performance of the different risk functions, receiver-operator characteristic (ROC) curves were constructed. ROC curves characterize the relationship between sensitivity and 1 - specificity. The sensitivity of a test is the probability $(0-100 \%)$ that the test is positive for subjects with diabetes. The specificity is the probability that a test is negative for subjects without diabetes. The area under the ROC curve quantifies how well the test correctly distinguishes a subject with diabetes from a subject without diabetes; the larger the area under the curve, the better the performance of the risk function. The Epistat package was used to construct the ROC curves and their $95 \%$ Cls.

At different cutoff points of the predictive models, the number of subjects who would need to be referred for further testing to diagnose diabetes was cal culated, as was the number of subjects with undiagnosed diabetes who would be missed. To be able to compare the performance of the three predictive models with previously reported studies (10-12), we used cutoff values yielding a specificity of $55 \%$.

\section{RESULTS}

Selection of the predictive models Compared with the nondiabetic subjects, the group of individuals with newly detected diabetes $(n=118)$ were more likely to be men and to have a higher BMI, WHR, and systolic blood pressure, to use more antihypertensive medication, and to have a family history of diabetes (Table 1 ). Chest pain was more preval ent among subjects with newly detected diabetes, as was pain during walking. Two-thirds of thesubjects with newly detected diabetes reported that they did not bicycle, compared with $40 \%$ of the nondiabetic subjects.

In the first predictive model (PM1) age, sex, presence of obesity, and use of antihypertensive medication were selected (Table 2 ). The second predictive model (PM2) also included family history of diabetes, BMI (continuous), and physical activity (operationalized as cycling). The variables obtained from physical examination (blood pressure and WHR) did not have an additive predictive value, resulting in a third predictive model (PM3) that was identical to the second one. The regression coefficients were transformed into scores. The age score showed that from age 55 onward, every increment of 5 years corresponded with an additional score of 2 points for PM 1 and 1 point for PM2. The aggregated score ranged from 0 to a maximum of 22 for PM 1 and from 19 to 60 for PM2.

Validation of the predictive models Both predictive models were evaluated in the Hoorn Study. In this study, 110 of 2,364 subjects had newly detected diabetes. The characteristics of the Hoorn population differed slightly from those of subjects studied in the Rotterdam Diabetes Study. The mean age of subjects with or without newly detected diabetes was lower ( 66.2 and 60.5 years). The proportion of women among the two groups was $47 \%$.

Table 3- Percentage of newly detected diabetes in both studies according to strata of the aggregated score of the two predictive models

\begin{tabular}{|c|c|c|c|c|c|}
\hline \multirow[b]{3}{*}{ Score } & \multirow{2}{*}{\multicolumn{2}{|c|}{ Prevalence }} & \multirow[b]{3}{*}{ Score } & \multicolumn{2}{|l|}{ PM2 } \\
\hline & & & & \multicolumn{2}{|c|}{ Prevalence } \\
\hline & Rotterdam Diabetes Study & Hoorn Study & & Rotterdam Diabetes study & Hoorn Study \\
\hline$<4$ & $18 / 227(8.6)$ & $10 / 606(1.7)$ & $<33$ & $10 / 239(4.4)$ & 14/869 (1.6) \\
\hline $4-6$ & $22 / 268(8.9)$ & $27 / 803(3.5)$ & $33-36$ & $17 / 188(9.9)$ & $20 / 497(4.1)$ \\
\hline $7-8$ & $23 / 180$ (12.7) & $9 / 269(3.5)$ & $37-41$ & $16 / 175(10.1)$ & $21 / 458(5.0)$ \\
\hline $9-10$ & $24 / 140(20.7)$ & $20 / 336(6.4)$ & $42-47$ & $30 / 216(16.1)$ & $20 / 343(6.2)$ \\
\hline$\geq 11$ & $31 / 174(20.9)$ & $44 / 350(14.4)$ & $\geq 48$ & 45/171 (35.7) & $34 / 197(21.0)$ \\
\hline Total & $118 / 989(13.5)$ & $110 / 2364(4.9)$ & Total & $118 / 989$ (13.5) & $110 / 2364(4.9)$ \\
\hline
\end{tabular}

Data are number of subjects with newly detected diabetes/total $n(\%)$. 


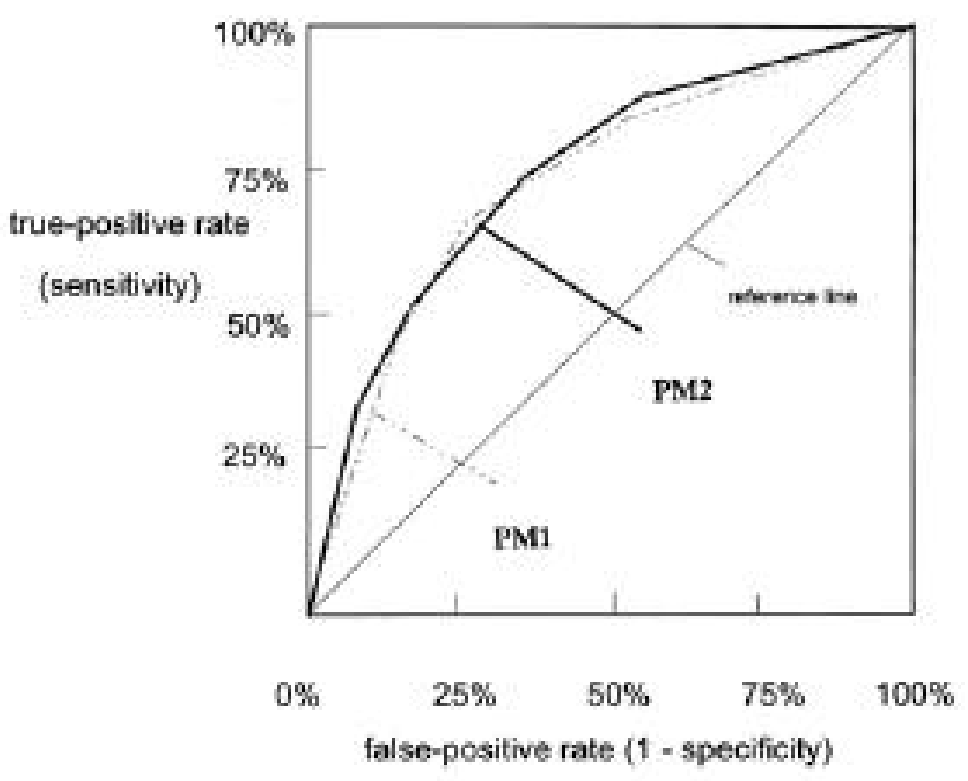

Figure 1-ROC curves for PM1 and PM2 (Hoorn Study).

The proportion of subjects with obesity among newly diagnosed diabetic and nondiabetic subjects was higher compared with the Rotterdam Diabetes Study (36.4 and 14.0 , respectively). The proportion of subjects using antihypertensive drugs was lower in the Hoorn Study (28.7 [newly detected diabetes] and 13.3\% [nondiabetic]), as was the percentage of subjects reporting that they did not cycle (41.3 and $23.6 \%)$.

In Table 3, the percentage of newly detected diabetes in the Rotterdam Dia betes Study and in the Hoorn Study is given according to strata of the aggregated score of the two predictive models. The percentage of newly detected diabetes increased with a higher score in both models. In the Rotterdam Study, $20 \%$ of the subjects with a score $\geq 9$ in PM 1 and $\geq 42$ in PM2 had newly detected diabetes. In the Hoorn study, the optimal cutoff point was $\geq 11$ in PM 1 and $\geq 48$ in PM 2 .

The area under the ROC curve was larger for PM 2 (0.74 [95\% CI 0.70-0.78]) compared with PM1 (0.68 [0.64-0.72]), but the confidence intervals overlap (Fig. 1). Of the 110 subjects $(63.6 \%)$ with newly detected diabetes, 70 had positive scores on both PM1 and PM2 when using the cutoff point of $\geq 6$ for PM 1 and $\geq 36$ for PM 2 .

With a specificity of $55 \%$, the positive predictive value (PPV) of PM 1 was $8 \%$, and that of PM2 was $7.2 \%$. When characterizing the false-positive subjects, $14.4 \%$ had IGT in PM1 and $13.9 \%$ in PM2 (Table 4).
The predictive models select subjects who should undergo further testing for diagnosing diabetes. In Fig. 2, the number of subjects required to undergo blood glucose testing (e.g., an OGTT) to find one diabetic subject is plotted against the different cutoff points of the predictive models. When no predictive model is used to select subjects with a higher risk of undiagnosed diabetes, 20.5 subjects would have to undergo an OGTT to find one diabetic subject (assuming a prevalence of undiagnosed diabetes of $5 \%$, as in the Hoorn Study). At higher cutoff points, fewer subjects have to be referred for further testing. However, the percentage of diabetic subjects missed will increase (Fig. 3).

CONCLUSIONS - We developed three predictive models for selecting subjects with an increased risk of having undiagnosed diabetes. In the first predictive model (PM1), we included only information readily available to the general practitioner. The variables age, sex, use of antihypertensive medication, and presence of obesity appeared to be predictive. In the second predictive model (PM 2), items that could easily be obtained by simple additional questions were included. A family history of diabetes and physical inactivity (in this Dutch study operationalized as bicycling) were included as risk factors in this model, of which the variables of the first model were also part. The third predictive model (PM3) was rejected, since the items obtainable by noninvasive measurements (blood pressure or WHR) had no additive predictive value in this study population, resulting in a PM3 similar to PM2. To gain more insight into the performance of the two predictive models, both were evaluated in another study population. The differences between the two models were rather small.

In the Rotterdam Study, $20 \%$ of the subjects with a score $\geq 9$ in PM 1 and $\geq 42$ in PM 2 had newly detected diabetes. In the Hoorn study, the optimal cutoff point was $\geq 11$ in PM 1 and $\geq 48$ in PM2. This is probably due to the fact that the differences in characteristics between newly diagnosed diabetic subjects and the nondiabetic subjects are larger in the Hoorn Study compared with the Rotterdam study. For example, the mean age in the Rotterdam study is 66.2 years for nondiabetic subjects and 67.8 years for diabetic subjects, whereas in the Hoorn study, the mean ages are 60.2 and 66.5 years, respectively.

In the first predictive model, obesity was defined as $\mathrm{BMI} \geq 30 \mathrm{~kg} / \mathrm{m}^{2}$, whereas in the second predictive model BMI was included as a continuous variable. Assuming that in real ity a general practitioner cannot exactly estimatewhether a person has a BMI below or above $30 \mathrm{~kg} / \mathrm{m}^{2}$, the predictive value of this variable will be lower in

Table 4- Performance of PM1 and PM2 (Hoorn Study)

\begin{tabular}{lcc}
\hline & PM 1 & PM2 \\
\hline Cutoff point & Score $>6$ & Score $>36$ \\
Performance of the predictive model & & \\
Specificity & 55 & 55 \\
Sensitivity & 78 & 72 \\
PPV & 8 & 7.2 \\
N egative predictive value & 98 & 98 \\
Characteristics of the false positives & & 14.4 (133 of 923) \\
\% of subjects with IGT $(n)$ & $14.7(130$ of 882)
\end{tabular}




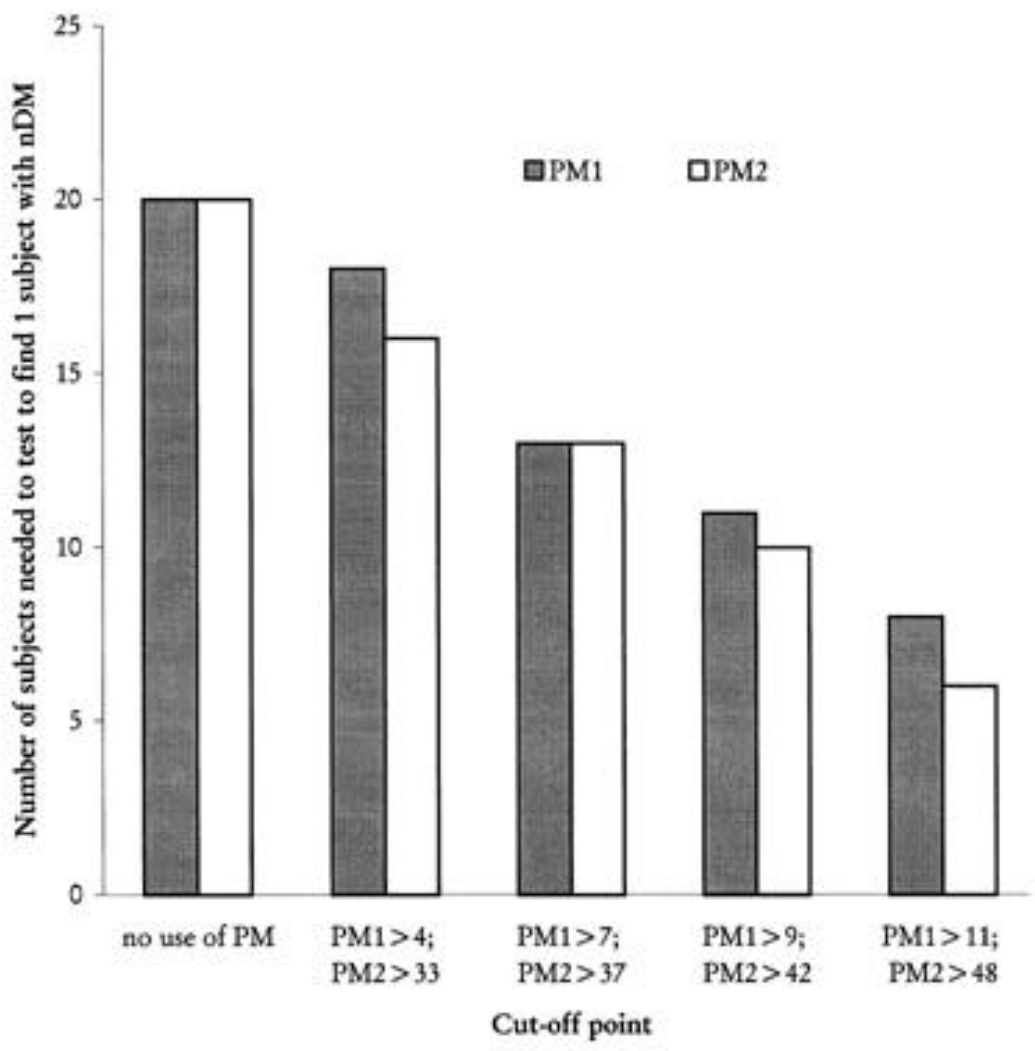

Figure 2-Effect of selecting subjects with a high risk of having undiagnosed diabetes, expressed as number of subjects that has to be referred for further testing to diagnose one diabetic subject.

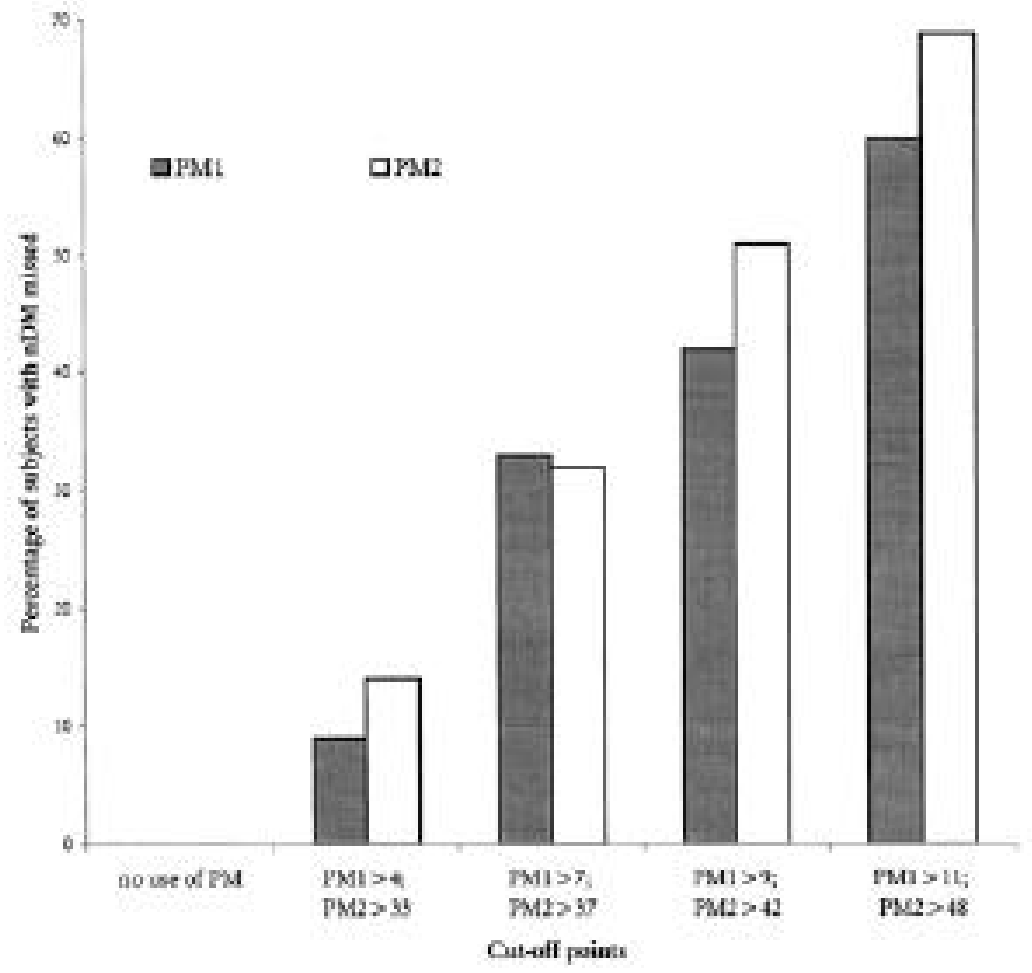
Figure 3-The percentage of undiagnosed diabetic subjects that will be missed when using PM developed that included age, sex, obesity, PM2. clinical practice. The performance of PM1 is thus slightly overestimated. However, the BMI used in PM2 will usually be based on self-reported height and weight instead of taking these measurements, as was the case in this study. It has been shown that selfreported height and weight lead to an underestimation of the BMI $(18,19)$, and this underestimation tends to be higher in more obese subjects than in lean ones (20). It is not clear whether this will influencethe predictive value of PM2, but the performance of PM2 is likely to be slightly overestimated. When using the categorical variable obesity instead of the continuous variable in the PM2, the performance of this model did not change (data not shown).

Physical activity was a highly discriminative variable between subjects with and without diabetes, an observation also reported in other studies $(9,11)$. As has been shown in a previous study (14), cycling was the variable that contributes most to the discrimination in the Netherlands. We have chosen to use cycling as a variable in the PM2, since now the subject only has to answer one simplequestion, whereas when using the more broad and vague variable physical activity," a number of questions have to be answered to arrive at a score. Obviously, in other countries, different activities will contribute to total activity.

Considering the small differences between the two predictive models in performance, and the simplicity of the first one, PM1 seems to be the most appropriate predictive model to use in the current health care setting. The variables selected for PM1 are very logical from a clinical point of view and, since most general practices are computerized, it will be easy to identify the subjects with a positive score on PM 1 by the computer.

Several other tools for screening undiagnosed diabetes have been developed in earlier studies. The ADA suggests that everyonewith more than onerisk factor for diabetes (family history of diabetes, obesity, an at risk race, hypertension, significant hyperlipidemia, or a history of gestational diabetes or delivery of heavy babies) should be referred to the general practitioner and tested for diabetes (9). Herman et al. (11) developed a classification tree in which age, physical inactivity, family history of diabetes, and having given birth to a heavy baby were predictive variables. In the Hoorn Study (12), a questionnaire was physical inactivity, frequent thirst, and some 
cardiovascular symptoms. The questionnaires differ in the number of risk factors, but all include age, sex, and family history of diabetes. In our study, no obstetrical questions were asked, and thus the variable "delivery of heavy babies" could not be included in the analysis.

The performance of the reported tools has been compared by Ruige et al. (12) in yet another Dutch population-based study with a prevalence of newly detected diabetes similar to that of the Hoorn Study. PPVs ranged from 5 to $7 \%$, which is comparable to the PPVs of our PM1 (8\%) and PM2 (7.2\%). The choice of the cutoff values ensured that the specificity was $\sim 55 \%$ for all tools to facilitate a comparison between the PPVs. These low PPV s place into question the usefulness of a tool for selection of subjects with high risk for undiagnosed diabetes. On the one hand, they are simple and easy to use. Without much effort, the population to be tested for diabetes (using a blood glucose measurement) can be reduced. They are, moreover, useful in making the general practitioner and the patients more attentive to the problem of undiagnosed diabetes. For example, the possibility of having undiagnosed diabetes seems to be underestimated in men, considering the high score of this variable in both predictive models (score $=5$ in PM 1 and 7 in PM2). After selection of a high-risk group, a large number of people will nonetheless turn out not to have diabetes, depending on the cutoff point used. In addition, a number of subjects with undiagnosed diabetes will be missed, since they will have a score below the cutoff point.

In the development and evaluation of the questionnaires, attention has only been paid to screening of undiagnosed diabetes. However, there will also be a number of subjects with IGT. In the Hoorn Study, $15 \%$ of the subjects who scored positively on the first predictive model had IGT, using a cutoff point of 6 . These subjects have been shown to have an increased risk for developing diabetes (21), as well as an increased risk for (macrovascular) complications (22-24). Intervention strategies in people with IGT or other high-risk characteristics may prevent or delay type 2 diabetes $(25,26)$. More insight into this question will be obtained from the Diabetes Primary Prevention Trial, in which treatment of people with high-risk characteristics such as IGT will be tested (27).

To conclude, the predictive models can be used to identify subjects with a higher risk for having undiagnosed diabetes. Both of the predictive models we developed may easily be used in the current health care setting. However, from a pragmatic point of view, PM 1 seems to be the most appropriate predictive model. Until the discussion is solved about who, when, and how to screen for undiagnosed diabetes on a community-wide basis, general practitioners can use PM 1 to determine which of their patients have a higher probability of having undiagnosed diabetes.

Acknowledgments - This study is part of a research project supported by grants from the National Institute for H ealth Sciences (NIHES).

\section{References}

1. King $H$, Rewers $M$ : Global estimates for prevalence of diabetes mellitus and impaired glucose tolerance in adults. Dia betes Carel6:157-177, 1993

2. Harris MI: Undiagnosed NIDDM: clinical and public health issues. Diabetes Care 16:642-653, 1993

3. Mooy JM, Grootenhuis PA, de Vries $H$, Valkenburg HA, Bouter LM, Heine RJ: Prevalence and determinants of glucose intolerance in a Caucasian population: the Hoorn Study. Diabetes Care18:1270-1273, 1995

4. Stolk RP, Pols HAP, Lamberts SWJ, Jong de PTVM, Hofman A, Grobbee DE: Diabetes mellitus, impaired glucose tolerance and hyperinsulinemia in an elderly population: the Rotterdam study. Am J Epidemioll45: 24-32, 1997

5. Balkau B, Eschwege E, Papoz L, ClaudeJR, Warnet JM, Ducimetiere P: Risk factors for early death in non-insulin-dependent diabetes and men with known glucose tolerance status. Br Med J 307:295- 299, 1993

6. Klein R: Hyperglycemia and microvascular and macrovascular disease in diabetes. Dia betes Care18:258-268, 1995

7. Harris MI, Modan M: Screening for NIDDM: why is thereno national program? Diabetes Care17:440-444, 1994

8. Paterson KR: Population screening for diabetes mellitus. Diabet Med 10:777-781, 1993

9. American Diabetes Association: Screening for type 2 diabetes (Position Statement). Diabetes Care21 (Suppl. 1):S20-S22, 1998

10. American Diabetes Association: American diabetes alert. Diabetes Forecast46:54-55, 1993

11. Herman WH, Smith PJ, Thompson TJ, Engelgau MM, Aubert RE: A new and simple questionnaire to identify people at increased risk for undiagnosed diabetes. Diabetes Care18:382-387, 1995

12. Ruige JB, N eeling de JND, Kostense PJ,
Bouter LM, Heine RJ: Performance of an NIDDM screening questionnaire based on symptoms and risk factors. Diabetes Care 20:491-496, 1997

13. Hofman A, Grobbee DE, de Jong PVTM, van den Ouweland FA: Determinants of disease and disability in the elderly: the Rotterdam Elderly study. Eur J Epidemiol 7:403-422, 1991

14. Baan CA, Stolk RP, Grobbee DE, Witteman JCM, Feskens EJM: Physical activity in elderly subjects with impaired glucose tolerance and newly diagnosed diabetes mellitus. Am J Epidemiolln press

15. World Health O rganization: Diabetes Melli tus: Report of a WHO Study Gap Geneva, World Health Org., 1985, p. 1-113 (Tech. Rep. Ser., no. 727)

16. Rose G, Blackburn H: Cardiovascular Suvey M ethodsGeneva, World Health Org., 1968 (WHO Monogr. Ser.)

17. Caspersen CJ, Bloemberg BPM, Saris WHM, Merritt RK, Kromhout D: The prevalence of selected physical activities and their relation with coronary heart disease risk factors in elderly men: the Zutphen Study 1985. Am J Epidemiol133: 1078-1092, 1991

18. Roberts RJ: Can self-reported data accurately describe the prevalence of overweight? Public Health109:275-284, 1995

19. Crawley HF, Portides G: Self-reported versus measured height, weight and body mass index amongst 16-17 year old teenagers. Int J Obes Relat Metab Disord 19:579-584, 1995

20. Jeffery RW: Bias in reported body weight as a function of education, occupation, height and weight concern. Addict Behav21:217222, 1996

21. Saad MF, Knowler WC, Pettitt DJ, Nelson RG, Charles MA, Bennett PH: A two-step model for development of non-insulindependent diabetes. Am J Med90:229-235, 1991

22. Fuller JH: Coronary-heart-disease risk and impaired glucose tolerance: the W hitehall Study. Lancet1:1372-1376, 1980

23. Rewers M, Shetterly SM, Baxter J, Marshall JA, Hamman RF: Prevalence of coronary heart disease in subjects with normal and impaired glucose tolerance and noninsulin-dependent diabetes mellitus in a biethnic Colorado population: the San Luis Valley Diabetes Study. Am J Epidemiol 135:1321-1330, 1992

24. Nijpels G, Popp-Snijders C, Kostense PJ, Bouter LM, H eine RJ: Cardiovascular risk factors prior to the development of noninsulin-dependent diabetes mellitus in persons with impaired glucose tolerance the Hoorn Study. J Clin Epidemio50:10031009, 1997

25. Eriksson KF, Lindgärde $F$ : Prevention of type 2 (non-insulin-dependent) diabetes mellitus by diet and physical exercise. Dia - 
betologia34:891-898, 1991

26. Tuomilehto J, Knowler WC, Zimmet P: Primary prevention of non-insulin dependent diabetes mellitus. Diabetes Metab Rev 8:339-353, 1992

27. Knowler WC: Screening for NIDDM: opportunities for detection, treatment, and prevention. Diabetes Care 17:445-450, 1994 